\title{
SUMMARISING THE NATIONAL INVENTORY OF SOUTH AFRICA FOR THE PUBLIC AND ITS APPLICATION IN HERITAGE MANAGEMENT
}

\author{
N.Mlungwana ${ }^{a}$, C.Jackson ${ }^{\mathrm{a}}$

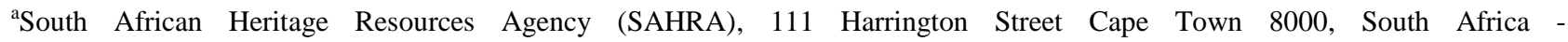 \\ nmlungwana@sahra.org.za
}

KEY WORDS: Inventory, Heritage Management, Public Data, Sites, NHRA, SAHRIS, Digitisation

\begin{abstract}
:
This paper will focus on the national inventory of South Africa and application in heritage management. The South African Heritage Resources Agency (SAHRA) is mandated to compile and maintain an inventory of the national estate, defined as heritage resources of cultural and other significance as per Sections 3 and 39 of the National Heritage Resources Act. No.25 of 1999. This inventory is presented in a form of a database facilitated through the South African Heritage Resources Information System (SAHRIS). SAHRA is also mandated to produce a summary and analysis of this inventory of the national estate at regular intervals as per Section 39(7) of the NHRA. This inventory and its subsequent publication facilitate accountability for the institution, access to the data by the public as well as public awareness. The national inventory is populated through numerous digitisation projects by various heritage institutions namely museums, galleries, Provincial Heritage Resources Authorities (PHRA's) and the public at large.
\end{abstract}

\section{INTRODUCTION}

\subsection{About SAHRA}

SAHRA is a statutory body under the South African Department of Arts and Culture (DAC). SAHRA is established under the NHRA no 25 of 1999 and is tasked with protecting South Africa's cultural heritage. The mandate is to coordinate the identification and management of the National estate (SAHRA, 2017a). SAHRA does this in conjunction with Provincial and local authorities. SAHRA formulated units that focus on specific sections of the NHRA. SAHRA is also responsible for setting norms and standards for best practice in heritage resources management. These may be published nationally or may be disseminated practically, for example, though assessment of, and interaction with, the Provincial Heritage Resources Authorities (PHRAs), which should have been fully established from 2002. SAHRA is also directly responsible for the identification, protection, conservation and monitoring of Grade I heritage resources (SAHRA, 2010b).

\section{THE NATIONAL INVENTORY}

\subsection{SAHRIS and populating the inventory}

Section 39 of the NHRA specifically mandates SAHRA to build and maintain a database of all heritage resources that form part of the National estate, which is define as "those heritage resources of South Africa which are of cultural significance or other special value for the present community and for future generations must be considered part of the national estate and fall within the sphere of operations of heritage resources authorities." (South Africa, Dept. of Arts and Culture, 1999).

The makeup of this inventory must include:

- "all places and objects protected through the publication of notices in the National Gazette or
Provincial Gazette, whether in terms of this Act or provincial legislation;

- places and objects subject to general protections in terms of this Act or provincial legislation for the management of heritage resources;

- $\quad$ any other place and object which it considers to be of heritage significance; and

- all places and objects with which it and its predecessors have been involved. " (South Africa, Dept. of Arts and Culture, 1999).

SAHRIS is an Integrated Heritage Management System that provides a platform where all applications can be submitted, mapped and processed online. It acts as a National Heritage Sites Repository by hosting a database of sites recorded on heritage registers as well as those that have been newly identified by means of mandatory site recording on SAHRIS for impact assessment surveys. It also acts as a National Collections Management System by providing a free platform for the capturing of object descriptions, histories and photographs. It offers integrated permitting processes to govern the import and export of heritage objects. It also is a National Heritage Crimes Database by providing a feature for heritage crime applications to be uploaded, these applications triggers the attention of other departments e.g. South African Police Services (SAPS) and South African Revenue Services (SARS) Custom division. As theses heritage crimes are mapped out the police are able to see what the hot spots in heritage crimes are.

The information is recorded through the applications that the public lodge on the system whether it is permits for loaning objects for exhibitions in foreign countries, or uploading Impact Assessments for a comment by a heritage office. Museums are able to manage their collections on SAHRIS, this enables such institutions to even track movements of those objects. Through inventorising and digitising museum collections the national inventory is successfully populated. Researchers and fields workers are also able to record sites and their current state through the site recording feature. Developments are also mapped though the GIS enabled functionality, with a feature to 
track the Palaeontological sensitivity of the area. This also enables the tracking in the significant growth of development in the country. (Smuts et al., 2016).

This inventory is facilitated through the above mentioned SAHRIS system. Operationalising the inventory in this manner allows SAHRA to maintain an integrated record of heritage resources together with the research and management actions that are associated with the resource. This becomes a powerful tool for the monitoring of the condition of heritage resources within the republic.

Enshrined within the NHRA is the public nature of the inventory. This public accessibility is further emphasised through the requirement of a publication providing a summary and analysis of the inventory of the national estate, as stipulated in Section 39(7) (South Africa, Dept. of Arts and Culture, 1999). This provides an accessible tool through which the public at large and heritage management authorities can engage with trends and issues in the management of heritage resources.

This summary and analysis of the national estate has, until the 2016/2017 financial year, been a portion of the South African heritage legislation that has not been fully enacted. Whilst SAHRIS has facilitated a public interface to the inventory of the national estate, it is reliant on the user to conduct their own analysis and identify trends.

\subsection{Summarising the inventory of the national estate}

At the end of 2016 the National Inventory of South Africa contained 47307 sites and 27938 objects. For the purposes of this paper only the trends associated with sites and specifically Provincial Heritage Sites will be discussed (SAHRA, 2017f, SAHRA, 2017g).

As introduced in the preceding section, SAHRA is mandated in terms of the NHRA to produce, at regular intervals, a summary and analysis of the Inventory of the National Estate (South Africa, Dept. of Arts and Culture, 1999).

The information required in order to produce the summary and analysis of the inventory of the national estate already exists in a usable form, thanks to South Africa's development and adoption of SAHRIS it becomes a simpler, more cost effective and, ultimately, more sustainable exercise to publish he summary via an online portal attached to SAHRIS, than repeated paper based publication.

Noting the capacity constraints within the National Inventory unit, this portal will allow SAHRA to comply with South African legislation and maintain our obligation for public accessibility of data.

Using the data that is readily available through SAHRIS, we have been able to provide simplified statistics that can be used by members of the South African public to explore heritage, and more importantly this can be used by the country's heritage management institutions to identify trends and guide operations within their spheres of operation.

All sites loaded into the Inventory are assigned a specific "Site Type" based on the principle makeup of the site. These sites types were adapted from the Data Coding Standards that were produced for SAHRA in 2006 (Layton, 2006)
- Archaeological

-Artefacts

-Rock Art

-Deposit

-Shell Midden

-Ruin > 100 years

-Stone walling

-Settlement

- $\quad$ Living Heritage/Sacred sites

- Battlefield

- Burial Grounds \& Graves

- Conservation Area

- Cultural Landscape

- Geological

- Meteorites

- Monuments \& Memorials

- Natural

- Palaeontological

- Place

- $\quad$ Structures

-Bridge

-Building

-Transport infrastructure

- Underwater

-Shipwreck

-Submerged

--Intertidal

--Partially submerged

--Fully submerged

Some sites represent more than one of the above mentioned Site Types, however for the purposes of providing a simplified snapshot through which people can engage with heritage resources the site type has been simplified to utilise only the principle site type for which the site is recognised. In addition to this, only parent terms were use, for example where a site may principally be a rock art site, this is recorded here as "Archaeological".

For the purposes of this paper, it was decided to focus on heritage sites that are recognised as declared provincial heritage sites and sites that fall under the general protections of the NHRA. This is based on the sheer quantity of provincial heritage sites in South Africa

Under section 58(11a) of the NHRA all heritage sites declared under previous heritage legislation were deemed to be Provincial Heritage Sites, and included a stipulation that all of these now "Provincial Heritage Sites" were to be reassessed for possible declaration as National Heritage Sites (South Africa, Dept. of Arts and Culture, 1999). 


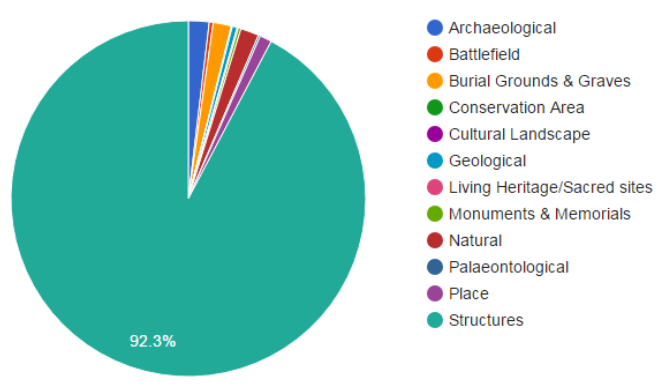

Figure 1: Chart showing the breakdown of declared Provincial Heritage Sites based on site type (SAHRA, 2017e).

Performing a visualisation as simple as the above shows that 92.3\% of declared Provincial Heritage Sites in South Africa reside within the built environment, or "Structures" as it is labelled here (SAHRA, 2017e). This when compared to the general makeup of the inventory shows a stark imbalance in the inventory with only $24.4 \%$ of identified heritage sites residing in the built environment. Though it is important to note that this only a superficial analysis and does not speak to the significance of the various sites. Providing this simplified and more accessible level of data then becomes toll that can be used by the public in order to readily see if they are represented within the heritage landscape of the country.

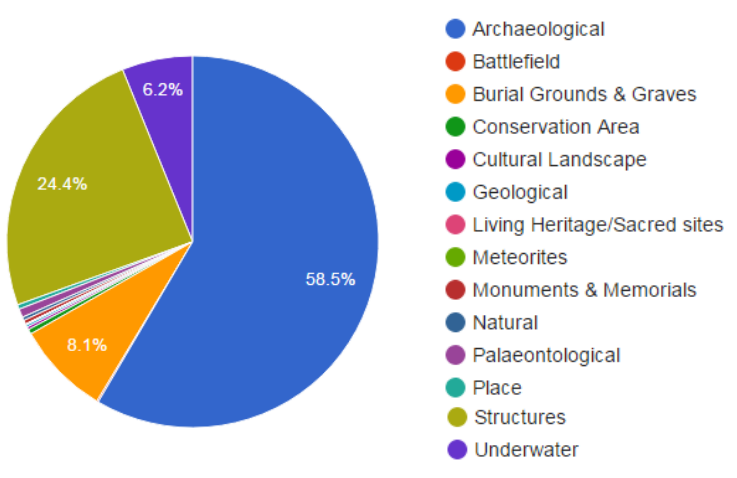

Figure 2: Chart showing the makeup of the inventory of protected sites by site type (SAHRA, 2017).

\subsection{An Inventory for management purposes}

An inventory of the national estate plays a crucial role for developers in their planning stages, they are able to verify what are the protected areas, listed properties etc. Whether sites are of national or provincial significance, which areas are the conservation areas? They are able to obtain as much relevant information as possible about sites all in one place because SAHRIS enables effective recording of this information. Furthermore, integrating the national inventory with the management system of South Africa we are able to analyse the types of developments occurring within the country and their impact on heritage resources.

The below chart shows that general electrical infrastructure is currently the largest component of development applications received on SAHRIS in the 2016 year, with mining applications following at $9.7 \%$ (SAHRA, 2017h).

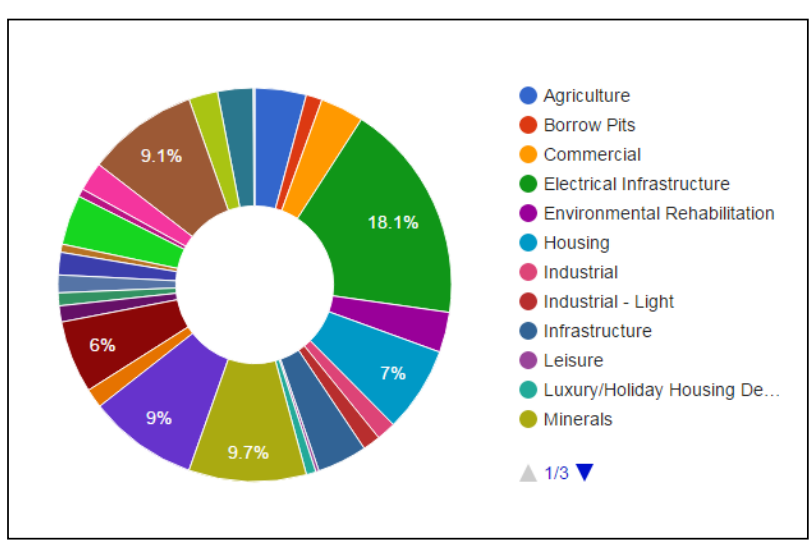

Figure 3: Development reporting in the national inventory (SAHRA, 2017h).

\subsection{Problems encountered}

The biggest challenge hindering SAHRA in managing the heritage to its maximum capacity is lack financials resources, most units are under staffed as a result one officer deals with un manageable amount of applications. That leads to an inability to not meet all the deadlines for applications. Another challenge is the incapacity of PHRA's currently there are only 3 PHRA's functioning out of the 9 Provinces. This results in SAHRA's heritage officers having to deal with these applications on behalf of the PHRA's. This problem also contributes in not meeting the 21 days turnaround time necessary to comment on applications. This has a further impact on the ability of the National Inventory to maintain an accurate record of heritage resources in the republic, as in many cases provincial authorities are simply not able to comply with the legislated reporting responsibilities.

\section{CONCLUSION}

In spite of all the challenges SAHRA is faced with the efforts of managing the national estate well are evident and the country is enjoying those benefits. Be it developers being provided with access to information that will assist them to make informed decisions or preventing illegal export of valuable objects to foreign countries because SAPS and Customs have all the relevant information to perform their duties.

\section{REFERENCES}

Department of Arts and Culture, South Africa, 1999. National Heritage Resources Act 25 of 1999. Government Gazette, 506(19974), Pretoria, Government Printers

Layton, R., 2006. SAHRIS Data Coding Standard. Unpublished internal document.

Smuts, K. Mlungwana, N. and Wiltshire, N. 2016. SAHRIS: South Africa's integrated, web-based heritage management system. Journal of Cultural Heritage Management and Sustainable Development. , Vol. 6 Issue: 2, pp.138-152, doi: 10.1108/JCHMSD-01-2016-0002

South African Heritage Resources Agency (SAHRA), 2017e. Provincial Heritage Sites. http://www-

dev.sahra.org.za/sahris/Inventory/PHS (18 May 2017) 
South African Heritage Resources Agency (SAHRA), $2017 \mathrm{f}$.

Object Browser http://www.sahra.org.za/sahris/object-browser (18 May 2017)

South African Heritage Resources Agency (SAHRA), 2017g. All Sites Finder. http://www.sahra.org.za/sahris/allsitesfinder (18 May 2017)

South African Heritage Resources Agency (SAHRA), 2017h. Development Types. http://www-

dev.sahra.org.za/sahris/inventory/development-types (18 May 2017)

South African Heritage Resources Agency (SAHRA), SAHRA, 2017c. Publication of the National Inventory. SAHRA http://www-dev.sahra.org.za/sahris/Inventory/Home (18 May 2017)

South African Heritage Resources Agency (SAHRA),SAHRA, 2017a. About SAHRA. SAHRA http://www.sahra.org.za (18 May 2017).

South African Heritage Resources Agency (SAHRA). 2010b.

Combing the Act. Unpublished internal document.

South African Heritage Resources Agency (SAHRA). 2017d.

Types Of Sites In The Inventory Of The National Estate. http://www-dev.sahra.org.za/sahris/inventory/sites-type (18

May 2017) 